\title{
The nature of positive post-diagnostic support as experienced by people with young onset dementia.
}

1) Vasileios Stamou, Centre for Applied Dementia Studies, Faculty of Health Studies, University of Bradford, Horton A Building, Richmond Road, Bradford, BD7 1DP, UK, email: v.stamou@bradford.ac.uk, ikaros1111@gmail.com, tel.: 00441274233 994, ORCID ID: https://orcid.org/0000-0001-8061-8246

2) Jenny La Fontaine, Centre for Applied Dementia Studies, Faculty of Health Studies, University of Bradford, Bradford, BD7 1DP, UK, email: j.lafontaine@bradford.ac.uk, ORCID ID: https://orcid.org/0000-0002-5485-0719

3) Mary O'Malley, Centre for Applied Mental Health Research, Faculty of Health and Society, University of Northampton, Northampton, NN1 5PH, UK, email: mary.o'malley@northampton.ac.uk, ORCID ID: https://orcid.org/0000-0003-3636-6197

4) Bridget Jones, Surrey Health Economics Centre, Department of Economics, University of Surrey, Guildford, Surrey, GU2 7XH, UK, email: b.e.jones@surrey.ac.uk, ORCID ID: https://orcid.org/0000-0001-9709-1794

5) Heather Gage, Surrey Health Economics Centre, Department of Economics, University of Surrey, Guildford, Surrey, GU2 7XH, UK, email: h.gage@surrey.ac.uk, ORCID ID: https://orcid.org/0000-0002-2049-9406

6) Jacqueline Parkes, Centre for Applied Mental Health Research, Faculty of Health and Society, University of Northampton, Northampton, NN1 5PH, UK, email: jacqueline.parkes@northampton.ac.uk, ORCID ID: https://orcid.org/0000-0003-2822-3049

7) Janet Carter, Division of Psychiatry, Faculty of Brain Sciences, Maple House, University College London, London, W1T 7NF, UK, email: j.carter@ucl.ac.uk, ORCID ID: https://orcid.org/0000-0002-4122-6132

8) Corresponding author: Jan Oyebode, Centre for Applied Dementia Studies, Faculty of Health Studies, University of Bradford, Bradford, BD7 1DP, UK, email: j.oyebode@bradford.ac.uk, ORCID ID: https://orcid.org/0000-0002-0263-8740 


\section{Funding}

This work was supported by the Alzheimer's Society under grant number 278 AS-PG-15b-034.

\section{Acknowledgements}

The research team acknowledges the support of the National Institute for Health Research Clinical Research Network (NIHR CRN). The research team would also like to thank all the members of the project Patient and Public Involvement Group and Steering Committee for their valuable advice and contribution, as well as the NHS sites and third-sector organisations, which facilitated the recruitment of participants to the study.

\section{Disclosure of interest}

The authors report no conflict of interest.

\section{Data availability statement}

The data that support the findings of this study are not available due to containing information that could compromise the privacy of research participants.

Word count: 5769 words 


\section{Abstract}

Objectives: Studies on service needs of people with young onset dementia have taken a problem-oriented approach with resulting recommendations focusing on reducing service shortcomings. This study aimed to build on 'what works' in real-life practice by exploring the nature of post-diagnostic support services that were perceived positively by younger people with dementia and carers.

Method: Positive examples of support were gathered between August 2017 and September 2018, via a national survey. Inductive thematic analysis was employed to explore the nature of positively experienced services provided for younger people with dementia, including analysis of what was provided by positively experienced services. Results: Two hundred and thirty-three respondents reported 856 positive experiences of support. Data analysis yielded eight themes regarding the objectives of positive services: Specialist Advice and Information on Young Onset Dementia, Access to Ageappropriate Services, Interventions for Physical and Mental Health, Opportunities for Social Participation, Opportunities to Have a Voice, Enablement of Independence while Managing Risk, Enablement of Financial Stability, and Support Interventions for family relationships.

Conclusion: The study findings (a) suggest that positive services may collectively create an enabling-protective circle that supports YPD to re-establish and maintain a positive identity in the face of young onset dementia, and (b) provide a basis from which future good practice can be developed.

Keywords: young onset dementia, carers, Alzheimer's, frontotemporal dementia, service design 


\section{Introduction}

Despite the increased focus of health and social care policies on reducing the impact of dementia on the health and well-being of those affected, people diagnosed under 65 years of age and their families have been largely neglected and face significant challenges in gaining access to support that is appropriate to their younger age and specific needs (Prince et al., 2014). Young onset dementia (onset before 65) affects approximately 42,500 people in the UK, accounting for 5-9\% of all dementia (Prince et al., 2014). The median annual cost of care for people with young onset dementia has been reported to be almost twice that for people with late onset dementia (Kandiah et al., 2016). Indirect costs, such as those resulting from loss of employment, contribute heavily, while young onset frontotemporal and vascular dementia, which occur more frequently in people under 65 , are associated with the highest costs (Kandiah et al., 2016).

Young onset dementia is significantly different from dementia with late onset, due to large variation in aetiology (Engedal \& Laks, 2017). The complexity of symptom presentation (Kelley, Boeve, \& Josephs, 2009) and the lack of awareness among health care professionals that dementia can occur at a younger age (Johannessen \& Möller, 2013) largely account for the average 4.4 year delay in receiving a diagnosis (van Vliet et al., 2013). Furthermore, younger people with dementia (YPD) have different post-diagnostic needs compared to older counterparts (National Institute for Health and Care Excellence [NICE], 2018), due to differences in age, life and family life stage (Millenaar et al., 2016). For instance, many YPD need to maintain a more physically active lifestyle and may be caring for dependent offspring or parents (Roach, Drummond, \& Keady, 2016), or resolving employment or financial issues (Chaplin \& Davidson, 2016). Alongside this, the negative social stereotypes and challenges 
imposed by young onset dementia can impact on identity, social relationships and family dynamics (Caddell \& Clare, 2011; Johannessen, Bruvik, \& Hauge, 2015; Hutchinson, Roberts, Daly, Bulsara, \& Kurrle, 2016). Quality of life of YPD can therefore significantly deteriorate without timely age- and needs-appropriate support (Baptista et al., 2016).

Previous studies have explored the availability of age-appropriate services (Cations et al., 2017; Mayrhofer, Mathie, McKeown, Bunn, \& Goodman, 2017), identified the needs of YPD and their families (Beattie, Daker-White, Gilliard, \& Means, 2002; Clemerson, Walsh, \& Isaac, 2014; Greenwood \& Smith, 2016; Millenaar et al., 2016; Rabanal, Chatwin, Walker, O'Sullivan, \& Williamson, 2018; Ramluggun \& Ogo, 2016) and provided recommendations on needs-appropriate support (Roach, Keady, \& Bee, 2012). Most have taken a problemfocused approach, exposing the shortcomings of services and providing important insights. To complement this, evidence of 'what works' in real-life practice could inform the development of evidence-based recommendations on service design and delivery, facilitate the provision of age-appropriate support for YPD, and reduce care costs (Roach \& Drummond, 2014). Mayrhofer et al. (2017) recently employed the 'what works' approach in a systematic review of the availability of age-appropriate services for young onset dementia. The primary studies reviewed $(n=10)$ spanned 26 years and included only seven that were UK-based. Similarly, evidence from just seven small-scale studies with YPD and carers (sample sizes, 5-28) was taken into account during the development of the recent NICE guidelines. The dearth of studies reflects the lack of high-quality evidence to inform good practice in post-diagnostic support for young onset dementia (NICE, 2018) and the need for further research including studies that represent the voices of younger people with dementia, to inform service design (Mayrhofer et al., 2017). 
Named after a person affected by young onset dementia, the Angela Project, a national UKbased study, aimed to develop guidance on good practice in diagnosis and post-diagnostic support for young onset dementia. To inform post-diagnostic support guidance, we conducted a national survey of positive experiences of services, service use, costs, and service satisfaction; conducted interviews and focus groups to understand underlying needs met; and interviewed service providers and commissioners, to explore barriers and facilitators to service provision. One objective of the survey was to gain understanding of positive experiences of postdiagnostic support for YPD and findings related to this objective are presented in this article, which reports on what is provided by positively experienced post-diagnostic services for younger people with dementia. Further findings, incorporating interview data and a proposed needs-based framework for good practice, will be separately reported.

\section{Methods}

This part of the Angela Project involved a national cross-sectional semi-structured anonymous survey, which gathered qualitative data that was subject to inductive thematic analysis. The study was approved by the Health Research Authority in England (South Central Berkshire Research Ethics Committee, REC ref.: 17/SC/0296).

\section{Recruitment}

Recruitment to the UK-wide survey took place through 14 purposively selected National Health Service sites across England, reflecting the breadth of diagnostic arrangements for YPD, i.e. young onset dementia services, age-generic dementia services and neurology services. In addition, it was advertised through Join Dementia Research, websites and newsletters of a wide 
range of UK-based third-sector organisations and through social media. There was no predefined sample size as the study was exploratory.

\section{Participants}

Those invited to take part had received a diagnosis of dementia, as defined by DSM-5 (American Psychiatric Association, 2013), before the age of 65, or cared for a younger person with dementia. (In the remainder of this paper the term 'carer' is used to mean a family member supporting or providing care for YPD. We use the term 'paid carer' for health or social care practitioners.) People with dementia caused by HIV, traumatic brain injury, Down's syndrome, Huntington's disease or alcohol-related dementia were excluded as they usually access different specialist services. We sought to recruit as many respondents as possible, including people with different subtypes of young onset dementia. All participants were provided with a list of nationwide sources of support.

\section{The survey}

The survey was conducted across the UK between August 2017 and September 2018. It was constructed by the researchers and had three sections, gathering data on (i) positive experiences of services and support for YPD and family members/carers respectively (ii) service use and satisfaction (iii) socio-demographic characteristics. The data from the questions on positive experiences of post-diagnostic services for YPD are the subject of this paper. To elicit rich responses, we asked open-ended questions which invited detailed information about positive experiences with services during the year after diagnosis and between the end of first year and the date of survey completion. The survey was piloted with YPD and carers from the project 
Patient and Public Involvement Group using three formats (on-line, on paper and face-to-face). Cognitive interviews (Willis, 2004) addressed survey content, format, length and wording, and helped to ensure that the questions elicited the data needed to meet the study objectives. In the light of feedback, the survey was revised, refined and piloted once more before being released.

The data from the questions on positive experiences of post-diagnostic services for YPD are the subject of this paper. To elicit rich responses, we asked open-ended questions. In response to feedback we positioned these near the start of the survey, as pilot participants indicated that the open-ended format required considerable thought and the questions were best placed when respondents would have most energy to recall experiences. (Later closed questions on service use were seen as less demanding). The first question pertinent to this article was: "During the year after the diagnosis, you may have needed help from professionals or volunteers for various reasons. This may have included for example, support to maintain your health, to stay at home, to maintain your quality of life or to maintain your social life. Can you think of times when the help and assistance you received was helpful? If yes, please provide a detailed description of these experiences. We would like to know: a) what was helpful? b) who was it helpful for? c) why was it helpful? d) who was involved (e.g. social worker, family doctor, nurse, etc.)? e) what was the name of the service(s)?" Following this, participants were invited to "to tell us about another experience of helpful assistance during the year after the diagnosis" and then to respond to the same questions with respect to the time period between the end of the first year following diagnosis to the current day. We developed with our PPI group, a sheet with cues to assist YPD to recall experiences. This suggested that positive experiences might include a service or form of support, advice or information, or the approach or attitudes of a person who has provided help. Where a carer was involved we asked the carer to give "examples of help and assistance that have benefited either or both of you, with priority to examples of services 
and support that have benefited the person you care for." (Separate questions were asked about support that benefitted families; this material is not included here.)

\section{Procedure}

The survey was available on paper and via the Bristol Online Survey Tool (https://www.onlinesurveys.ac.uk), which requires minimum computer literacy. It could be completed by YPD alone, with help from a paid carer, jointly with a family carer or by a carer alone. It could also be completed with the help of a researcher via phone or face-to-face, at participants' request. Where carers were involved, participants were asked to report examples of support that had benefited YPD, not support that carers had found positive primarily for themselves. (Separate questions were asked about support that benefitted carers; this material is not included here.) Participants who took part online and on paper were deemed to have capacity and to have consented by virtue of survey completion. Where participants completed the survey with the help of a researcher, capacity to consent was assessed and written consent was obtained in accordance with the Helsinki Declaration. None of the participants were deemed to lack capacity to consent.

\section{Analysis}

Descriptive analysis of socio-demographic data was carried out using SPSS 23 and qualitative data were analysed manually using inductive thematic analysis (Braun \& Clarke, 2006). Initially, two researchers engaged in repeated reading of the data and took notes about initial impressions. Data were then coded and continuous comparison and reflexive notes were used to determine consistency of the emergent coding scheme and identify potential bias related to 
the researchers' background. Different iterations were discussed and reviewed by the research team, ultimately leading to a coding scheme based on three major aspects of the positive examples of support: what was provided by services that were experienced positively, how positively experienced services were delivered, and why these were helpful for YPD. After analysing 502 positive examples, it was established that saturation had been reached as no further novel meanings, patterns, or themes emerged (Green \& Thorogood, 2004). Coding of an additional 50 purposively selected examples from participants with different types of dementia further confirmed this (Bowen, 2008).

The researchers refined the code descriptors and clustered the codes, by consensus, based on conceptual similarities, into what, how and why themes. The remainder of positive examples were then coded and the data were revisited to determine whether the final themes reflected accurately the meanings within the overall dataset. To explore whether there were major differences in the nature of positive examples given by YPD and family carers, we compared the contribution of different respondent groups to the themes and sub-themes. The final themes were presented to the project Patient and Public Involvement group and the wider research team to gain feedback on plausibility and coherence. This paper focuses on the what themes, describing what was provided by services that were positively experienced by younger people with dementia.

\section{Results}

After removing duplicates and cases that met exclusion criteria, data from 233 respondents, describing 856 positive examples of services/support, were analysed. Responses varied from detailed contextualised accounts to less extensive, brief, focused accounts. 
Socio-demographic details of the sample are given in Table 1 . It is noted that $48(21 \%)$ responses were provided by YPD alone or assisted by paid carers, $84(36 \%)$ were completed jointly by YPD and family carers, and $101(43 \%)$ were completed by a family carer alone.

[Table 1 about here]

Inductive thematic analysis led to eight themes related to what was provided by positively experienced services (see Table 2 for themes and sub-themes). Data from both YPD and family carers contributed to all themes and 20 sub-themes, while five sub-themes were derived only from examples of how carers thought the YPD had benefitted. Quotations are attributed to YPD or family carers as appropriate below.

[Table 2 about here]

\section{Specialist Advice and Information on Young Onset Dementia}

Services that provided advice and information specific to the younger age of onset and how to cope with symptoms were positively experienced, enabling YPD to understand their condition and adapt to life with the diagnosis. A younger person reported: 'The information that was given by my GP and the Young Dementia Team was helpful for me and my family. Everyone was in shock as I was only 46 years old ... They helped me and my family [to] cope.' In many cases, this involved sustained input from experts who had specialist knowledge of young onset dementia, in order to address emerging problems. Another younger person reported: 'We were able to meet regularly with the [specialist] consultant ... [we were] given the information we needed at every step of the journey.' 
Participants valued opportunities to receive in-depth information through education courses on young onset dementia, in order to understand future challenges and prepare accordingly. A younger person and carer reported: 'Attendance at [charity course] provided information for both of us, covering all aspects of living with young onset dementia, both clinical and legal etc. It was an invaluable insight into what laid ahead and enabled us to make arrangements.'

Respondents also emphasised the importance of having information on availability and access to age-appropriate services. A younger person and carer reported:

After diagnosis, me and my husband were invited to a [young onset] post-diagnostic group ... we were told all about services available for younger people, and how to get in contact with all the groups we could attend ... it helped us change direction.

Participants underscored the significance of having information about the process of claiming benefits, as most YPD were unable to maintain their employment and found it difficult to navigate services to find the necessary information or support. Two YPD reported: 'I've had to close my company down ... [Professionals] pointed me and my wife in the right direction to claim certain benefits ... It helped us to understand and move on.' and '[Charity] helped me with the Personal Independence Payment form. I obtained it without having to appeal like most people.'

Access to Age-appropriate Services

Services that helped YPD to acquire access to age-appropriate support were positively experienced. This often relied on referrals from knowledgeable professionals. A younger 
person reported: 'Social services referred me to the [Day Centre] specifically for young onset dementia .... It was very good and helpful ... Lots of support, socialising and could talk about any problems or worries. 'Referrals that led YPD to care provided by specialist teams appeared to be highly valued, as the latter provided a sense of security. A younger person and carer reported: 'Once we reached the Young Onset [locality] team everything changed for the better. The emotional support and care by the local young onset community team was great and constant.

Participants stressed the significance of having a professional who coordinated their care and access to services, according to their emerging needs. This role was undertaken by a link worker or other professionals who were part of collaborative networks of services. A carer wrote: 'Care has been lacking in the early days. This has improved greatly with time thanks to a link worker ... The post-diagnostic support was excellent and essential ...Without it we would have struggled.', and a couple responded: 'The occupational therapist has been helpful ... [he] has been middle-man between outpatient appointments, medication review and change of medication.'

\section{Interventions for Physical and Mental Health}

Survey respondents related positive experiences to services that aimed to enable YPD to maintain their physical and mental health. This was achieved through offering opportunities to address challenges with cognitive functions and physical health. A younger person reported a form of support which helped to maintain cognitive functions:

Towards the end of the first year after diagnosis I was invited by [memory clinic] to go on a cognitive stimulation therapy group course. This was so helpful, the advice given, 
the ideas for stimulation of the brain was a huge help to me and indeed are still practised by me.

An important aspect of maintaining mental health related to the prescription of medication, which can attenuate the expression of dementia symptoms. A carer reported: 'We also have an allocated psychiatrist ... She understands young onset dementia and is able to prescribe drugs that can minimise some of the more challenging symptoms of [husband's] particular dementia'.

Participants related how services which attended to individual physical needs helped to maintain physical health. Younger people with dementia at earlier stages mainly reported services which enabled them to stay physically active, whereas people at more advanced stages reported the benefits of support that helped to reduce the impact of dementia on their physical health. A younger person wrote: '[Charity volunteer service] offer me a mentor and we go on bike rides. This helps me get out and stay fit.' while a carer reported the value of specialist physiotherapy:

Because my husband walked so slowly, he was getting no aerobic exercise and was putting on weight and losing muscle tone and bulk... The physiotherapist was perfect, she explained how to do the exercises, repeated it until we both knew exactly what to do, and annotated the diagrams by hand for us ... his muscle tone and walking improved and his strength and flexibility also improved.

Opportunities for Social Participation 
Services that promoted active social participation were associated with positive experiences by most YPD. Respondents highlighted the benefits of social outings with peers in a similar situation. A younger person reported:

The group normally has about 6-8 of us and we go out and do fun things ... We've been to pubs for lunches, garden centres ... the beach ... for walks around churches, we have done all sorts of just fun things... It's really good because you can relax, you are amongst people that are just like you, you've got no worries. It's very buzzy, I always come away on a high.

The accepting social environment of peer support forums generated new social relationships and met social needs, including those that were gender-specific. A carer reported: 'A local charitable organisation started a monthly group for people with young onset dementia ... my husband was missing the company of other men and he has been able to make new friends.' Apart from the recreational aspect of camaraderie, YPD also emphasised the inclusive nature of age-appropriate forums which enabled them to feel held and supported by others who understood the challenges they faced and could help them to cope. One younger person reported:

I was given the opportunity to meet and talk with [others] of my own age group to compare experiences and views. They offered me understanding support when I needed it most... They made me feel useful instead of a burden.

In many cases, services provided transport to enable participation in social activities, as the ability of YPD to drive had declined and family carers were occupied during working hours due to their need to maintain their employment. A carer reported: 'It was particularly helpful 
that they were able to provide transport ... As I work full-time it would be difficult for me to be able to provide transport and due to the dementia, he no longer drives.'

\section{Opportunities to Have a Voice}

Younger people with dementia valued services which enabled them to have their voices heard, to make a difference in other people's lives. This was achieved through opportunities to take part in research projects, partnerships or networks, connected with young onset dementia. A younger person reported: 'I also work with [charity organisation] as an ambassador and with lots of other third-sector and NHS organisations and Universities on young onset dementia projects ... It gives me a sense of purpose and usefulness.' This example illustrates how opportunities for YPD to have their voices heard can promote a fulfilling sense of contribution. A younger person and carer further reported a network that enabled them to educate others living with the condition: 'We received an invitation ... to take part in a [national network] group, a way for raising awareness and training [others] newly diagnosed. The group makes my wife feel she is contributing.'

However, participants also reported cases where their voices were repeatedly ignored by services and other professionals had to come to their assistance to ensure they could receive the support they needed. A person with dementia and carer reported: '[The] care coordinator was able to advocate for us with social services and provide access to other services such as occupational therapy. [She] cut through some of the bureaucracy and helped social services to take our needs more seriously.'

Enablement of Independence while Managing Risk 
Participants emphasised the value of support that reduced the risk of harm for YPD, particularly at later stages of the condition. This was achieved via services that enabled independence, while managing risk. A carer reported the benefits of assistive technology in ensuring that the younger person could continue to go out of the house without fear of being lost: 'People from assistive technology have provided my husband with a mobile phone with GPS tracker. It helps if husband was lost and didn't come home, we could find where he was.'

An additional aspect related to minimising the risk of harm for YPD within their own residence. Participants placed a special focus on services that promoted stair safety and reduced the risk of accidental fire. A younger person wrote: 'I received a visit from an occupational therapist who advised me to have 2 rails up my stairs which has proved invaluable ... It meant reduced falls down [the] stairs for me', and a carer reported:

Memory clinic with fire service gave ways to improve our home to help decrease the risk of a fire. [They] gave guidelines in fire issues, e.g. plugs, cooking, in case of a fire what to do and what not to do.

\section{Enablement of Financial Stability}

Services that addressed the impact of YPD on household income were experienced as positive by many participants. Some of these services enabled YPD to continue working while living with the diagnosis. A carer reported: 'Occupational therapist tried to help keep partner in work, working out ways to assist him ... [She]also educated the other members of staff about his dementia and needs.' 
In many cases, employment loss occurred for YPD around the time of diagnosis. As a result, support with applying for benefits was valued (see Specialist Advice and Information on Young Onset Dementia theme), while couples also appreciated it when carers had understanding employers who provided them with the option of flexible working. A YPD responding with his wife reported: '[My] wife's employer was very supportive of variable hours, phones in meetings and working at home'.

Participants also reported positive experiences with services which helped them to locate additional financial support for external care. At the early stages, this was provided through gradually increasing funded home care. A carer reported: 'The social worker accessed our funding which pays for support services ... currently it's 12 hours per week ... We needed more practical support and without the social worker, [we] would have had to self-fund this.' At later stages, more intensive care could be funded via a personal health budget, offered by the National Health Service after appropriate assessments. A carer reported: 'Social Services, having found it very difficult to help us, recommended that we should apply for Continuing Health Care. This turned out to be hugely important decision ... [it] was game-changing.'

\section{Support Interventions for family relationships}

Participants reported positive experiences of services that addressed relational issues between the YPD and their main supporter. A carer whose husband was diagnosed with frontotemporal dementia reported how a service targeted to improve their communication was beneficial for their relationship:

We attended 7 sessions of speech, language and communication therapy together ... We had got into the habit of not communicating well, because it becomes more difficult 
with things like frontotemporal dementia ... It made such a difference in our relationship, because we learned how to communicate properly without getting all het up and then trying to hide it ... It's helped our relationship really, it's like relationship counselling.

Participants also described the benefits of services, which aimed to establish or restore a functional balance of roles and tasks within the family of younger people. A YPD reported:

[Local NHS] staff wrote a letter to explain to my family how I found it hard to say "no" to them and how best they could help me. The letter also talked about my scans and diagnosis ... [it] helped my family to take obligation of help away from me, so I could enjoy choosing what I could do. Now, I take my granddaughter shopping because I want to not because I have to.

\section{Discussion}

In this aspect of the Angela Project, we sought to understand what positively experienced services provide for people with young onset dementia. We conducted an inductive thematic analysis which identified eight themes, all of which were based on reports from both YPD and carers (about what the carer thought YPD experienced as positive). To the best of our knowledge, this is the first study of this scale to focus on what is provided by those services which are positively experienced by YPD.

The most pervasive themes were associated with services that enabled YPD to understand young onset dementia and how to cope with the changes it brings, to access age-appropriate services suitable for their social and physical/mental health needs, and to maintain or regain a sense of connectedness and reciprocity within family and age-appropriate social contexts. 
These themes have resonance with previous work. In their recent reviews, Mayrhofer et al. (2017) and Sansoni et al. (2016) summarised research on the experiences of YPD and listed interventions that have been reported as positive (e.g. football, gardening groups). These reviews (Mayrhofer et al., 2017; Sansoni et al., 2016) drew together findings on effectiveness from varied, mainly small-scale, intervention studies, whereas our own study took a contrasting approach by surveying the subjective service experiences of a wide range of YPD and family members. Six of our themes connect well with the findings of the reviews but two (Opportunities to Have a Voice; Enablement of Independence while Managing Risk) were not reflected, implying that they have not yet been addressed in intervention studies with YPD.

The finding that YPD appreciate services that 'Enable Independence while Managing Risk' may be connected to previous findings that YPD feel restricted when services or carers become concerned about risk (Beattie, Daker-White, Gilliard, \& Means, 2004; Holdsworth \& McCabe, 2018; Wawrziczny, Antoine, Ducharme, Kergoat, \& Pasquier, 2016). In this context, it is evident that a service which focuses on, for example using technology to contain risk while simultaneously enabling YPD to continue independent living, could be particularly valued. It is also noteworthy that only carers contributed to two of the related sub-themes. Possibly YPD were unaware of services that managed risk, precisely due to the over-protection they report experiencing or this could be related to the stigma and impact on sense of self of openly admitting basic safety issues.

Our study has enabled us to provide rich illustration of themes around positive service experiences. The inclusion of real-life examples, fleshes out some well-known concepts, for example, it may be well recognised that YPD wish to have opportunities for social participation (e.g. Pipon-Young, Lee, Jones, \& Guss, 2012), but the sub-themes and examples in our 
findings, imply that it is varied activities, in the community, that are normalised rather than being therapies, and that focus on enjoyment rather than coping with problems, which are positively experienced. This can give detailed ideas to providers on what to offer that is appropriate and will be positively experienced.

Previous papers have not included direct quotations from large samples of YPD on their service experiences, for example, Mayrhofer et al. (2018) confirmed from focus groups with YPD and family members that services were seen as useful if they met a wide range of needs. However, no direct quotations were included. Where positive service experiences have been reported, this has often been as a minor part of accounts that focus more broadly, as in Cations (2017) mixed-methods study which aimed to find out why YPD were not using services. Cations' focus group participants reported positive experiences of peer support, specialist case management and education courses about young onset dementia. All of these are reflected in our sub-themes, but our range of positive experiences is much broader.

A number of studies on lived experience have noted the disruption to identity brought about by young onset dementia and the need for a period of re-adjustment (Clemerson et al., 2014; Pipon-Young, Lee, Jones, \& Guss, 2012; Greenwood \& Smith, 2016). In this context, our study suggests what helps YPD to achieve re-orientation after diagnosis. Viewing our study findings together, the positive services appear to collectively create a sustaining protective-enabling 'safety net' (see Figure 1), through which YPD may feel supported to maintain important aspects of selfhood and identity. This indicates a potential underlying need for a web of services that minimises the disruption to the experience of self that occurs in dementia (Thorsen, Dourado, \& Johannessen, 2018). 
[Figure 1 near here]

Recommendations about the need for certain sorts of young onset dementia services are often put forward by researchers as a corollary to their findings on needs (e.g. Greenwood \& Smith, 2016) rather than being directly suggested by YPD themselves. An exception to this is Mayrhofer et al.'s (2018) recommendation for a community hub model, which was directly generated through discussions with 31 YPD and carers. However, this was a hypothetical ideal rather than being based on lived experience. In contrast, our study findings derive from reallife positive experiences with services.

The most recent NICE Guidelines (NICE, 2018) emphasise the potential importance of peer support, social activities, and services that help YPD to counteract their loss of agency and remain active and involved. The current study expands on this by showing more specifically what can be provided. For example, our themes of 'enablement of financial stability' and offering 'opportunities to have a voice' show what can be offered to counteract loss of agency. The eight emergent themes suggest the array of services that commissioners should be aiming to provide for YPD in the round (see Figure 1). These go beyond the NICE Guidelines by, for example, the inclusion of services that provide support interventions for family relationships and the care dyad. Our study findings could thus be used by service providers and commissioners to inform the design, improvement or evaluation of services for young onset dementia, which could be adjusted at a local level according to context and resources. The findings could also provide the basis for practitioners, YPD and their carers to co-develop individualised care plans based on the themes of what is positively experienced, that can be reviewed and adjusted over time. 
Although our study was UK-based, previous work has found similar needs across countries, such as Australia (Cations et al., 2017), Norway (Johannessen, A. \& Möller, A., 2013) and the Netherlands (Millenaar et al., 2016) and therefore it seems likely that aspects of our findings on service provision will also have international relevance. It would be interesting if future research could enable cross-country comparisons, to identify country- or culture-specific factors that influence the design and delivery of positive services.

Our study has both strengths and limitations. There was a high risk of selection bias, in favour of literate, educated participants who were in contact with support or services. To reduce bias, we advertised widely through NHS sites, third sector organisations and social media and made the survey accessible in different formats. Despite our sustained efforts, we received few responses from black and minority ethnic communities or YPD living in care homes or receiving end of life care. It is possible that cues to assist recall of YPD prompted examples of certain types of services which could have influenced the emergent themes, although the specificity in most of the responses gives credibility to the examples given. Additionally, the involvement of carers may have led to bias as carers may have not found it easy to take the perspective of the YPD they supported, even though we attempted to mitigate for this through clear instructions. The contribution of YPD and carers to 20/25 sub-themes lends some credibility to the findings, though five sub-themes came from carers alone. Additionally, the length of the survey may have discouraged some YPD from taking part or providing richer responses. However, the high number of responses, our inductive approach, and the high number of YPD with a wide range of ages, diagnoses, and social situations, may increase the trustworthiness and transferability of our findings and their potential to inform evidence-based recommendations for service design and delivery in young onset dementia. 
The following stages of the project included further analysis and additional follow-up interviews with survey respondents, to acquire an in-depth understanding of the needs met by positive services and the relationships among themes. The current study combined with the above actions have enabled us to develop needs-based Frameworks of Good Practice for services for YPD and carers, which will be reported separately.

\section{Conclusions}

In this paper, we have presented themes to show what was provided by services that were positively experienced by YPD and carers. A large sample of YPD contributed to our findings and the large number of positive examples of support show that YPD can identify positive experiences of post-diagnostic support in the UK. The emergent themes provide the basis from which specifically tailored support can be developed to address the unique challenges created for each individual living with young onset dementia. We hypothesise that when the services described by all eight themes are present, they can form an enabling-protective circle that supports YPD to re-establish and maintain a positive identity in the face of young onset dementia. 


\section{References}

American Psychiatric Association. (2013). Diagnostic and statistical manual of mental disorders. Arlington: American Psychiatric Publishing.

Baptista, M. A. T., Santos, R. L., Kimura, N., Lacerda, I. B., Johannenssen, A., Barca, M. L., ... \& Dourado, M. C. N. (2016). Quality of life in young onset dementia: an updated systematic review. Trends in Psychiatry and Psychotherapy, 38(1), 6-13. doi: $10.1590 / 2237-6089-2015-0049$

Beattie, A., Daker-White, G., Gilliard, J., \& Means, R. (2004). 'How can they tell?'A qualitative study of the views of younger people about their dementia and dementia care services. Health \& Social care in the Community, 12(4), 359-368. doi: 10.1111/j.1365-2524.2004.00505.x

Beattie, A. M., Daker-White, G., Gilliard, J., \& Means, R. (2002). Younger people in dementia care: a review of service needs, service provision and models of good practice. Aging \& Mental Health, 6(3), 205-212. doi:10.1080/13607860220142396

Bowen, G. A. (2008). Naturalistic inquiry and the saturation concept: A research note. Qualitative Research, 8(1), 137-152. doi: 10.1177/1468794107085301

Braun, V., Clarke, V. (2006). Using thematic analysis in psychology. Qualitative Research in Psychology, 3(2), 77-101. doi:10.1191/1478088706qp063oa

Caddell, L. S., \& Clare, L. (2011). I'm still the same person: The impact of early-stage dementia on identity. Dementia, 10(3), 379-398. doi:10.1177/1471301211408255

Cations, M., Withall, A., Horsfall, R., Denham, N., White, F., Trollor, J., . . Draper, B. (2017). Why aren't people with young onset dementia and their supporters using formal services? Results from the INSPIRED study. PLoS One, 12(7), e0180935. doi:10.1371/journal.pone.0180935 
Chaplin, R., \& Davidson, I. (2016). What are the experiences of people with dementia in employment?. Dementia, 15(2), 147-161. doi:10.1177/1471301213519252

Clemerson, G., Walsh, S., \& Isaac, C. (2014). Towards living well with young onset dementia: An exploration of coping from the perspective of those diagnosed. Dementia, 13(4), 451-466. doi:10.1177/1471301212474149

Engedal, K., \& Laks, J. (2017). Forekomst og risikofaktorer til demens i ung alder [Occurrence and risk factors for dementia at young age]. In A. Johannessen, L. M. Barca, K. Engedal, \& P. K. Haugen (Eds.), Yngre personer med demens-en laerebok. Tnsberg, Norway: Forlaget Aldring og helse

Green, J., Thorogood, N. (2004). Qualitative methods for health research. London: Sage Publications.

Greenwood, N., \& Smith, R. (2016). The experiences of people with young-onset dementia: A meta-ethnographic review of the qualitative literature. Maturitas, 92, 102-109. doi:10.1016/j.maturitas.2016.07.019

Holdsworth, K., \& McCabe, M. (2018). The impact of younger-onset dementia on relationships, intimacy, and sexuality in midlife couples: a systematic review. International psychogeriatrics, 30(1), 15-29. doi: $10.1017 / \mathrm{S} 1041610217001806$

Hutchinson, K., Roberts, C., Daly, M., Bulsara, C., \& Kurrle, S. (2016). Empowerment of young people who have a parent living with dementia: A social model perspective. International Psychogeriatrics, 28(4), 657- 668. doi:10.1017/S1041610215001714

Johannessen, A., Bruvik, F. K., \& Hauge, S. (2015). Family carers' experiences of attending a multicomponent psychosocial intervention program for carers and persons with dementia. Journal of Multidisciplinary Healthcare, 8, 91. doi:10.2147/JMDH.S76093 
Johannessen, A., \& Möller, A. (2013). Experiences of persons with early-onset dementia in everyday life: A qualitative study. Dementia, 12(4), 410-424. doi: $10.1177 / 1471301211430647$

Kandiah, N., Wang, V., Lin, X., Nyu, M. M., Lim, L., Ng, A., ... \& Wee, H. L. (2016). Cost related to dementia in the young and the impact of etiological subtype on cost. Journal of Alzheimer's Disease, 49(2), 277-285. doi:10.3233/JAD-150471

Kelley, B. J., Boeve, B. F., \& Josephs, K. A. (2009). Rapidly progressive young-onset dementia. Cognitive and Behavioral Neurology, 22(1), 22-27. doi:10.1097/WNN.0b013e318192cc8d

Mayrhofer, A., Mathie, E., McKeown, J., Bunn, F., \& Goodman, C. (2017). Age-appropriate services for people diagnosed with young onset dementia (YOD): a systematic review. Aging \& Mental Health, 22(8), 927-935. doi:10.1080/13607863.2017.1334038

Mayrhofer, A. M., Mathie, E., McKeown, J., Goodman, C., Irvine, L., Hall, N., \& Walker, M. (2018). Young onset dementia: Public involvement in co-designing community-based support. Dementia. doi: 10.1177/1471301218793463

Millenaar, J. K., Bakker, C., Koopmans, R. T., Verhey, F. R., Kurz, A., \& de Vugt, M. E. (2016). The care needs and experiences with the use of services of people with youngonset dementia and their carers: a systematic review. International Journal of Geriatric Psychiatry, 31(12), 1261-1276. doi:10.1002/gps.4502

National Institute for Health and Care Excellence. (2018). Dementia: Assessment, management and support for people living with dementia and their carers (NICE Quality Standard No. 97). Retrieved from https://www.nice.org.uk/guidance/ng97/evidence/fullguideline-pdf-4852695709 
Pipon-Young, F. E., Lee, K. M., Jones, F., \& Guss, R. (2012). I'm not all gone, I can still speak: the experiences of younger people with dementia. An action research study. Dementia, 11(5), 597-616. doi: 10.1177/1471301211421087

Prince, M., Knapp, M., Guerchet, M., McCrone, P., Prina, M., Comas-Herrera, A., ... Salimkumar, D. (2014). Dementia UK: Overview (2nd ed.). London: Alzheimer's Society

Rabanal, L. I., Chatwin, J., Walker, A., O'Sullivan, M., \& Williamson, T. (2018). Understanding the needs and experiences of people with young onset dementia: a qualitative study. BMJ Open, 8(10), e021166. doi:10.1136/bmjopen-2017-021166

Ramluggun, P., Ogo, E. (2016). Young onset dementia service provision and its effect on service users and family members. Mental Health Practice, 19(10), 15-19. doi:10.7748/mhp.2016.e1135

Roach, P., \& Drummond, N. (2014). 'It's nice to have something to do': Early-onset dementia and maintaining purposeful activity. Journal of Psychiatric and Mental Health Nursing, 21(10), 889-895. doi:10.1111/jpm.12154

Roach, P., Drummond, N., \& Keady, J. (2016). 'Nobody would say that it is Alzheimer's or dementia at this age': Family adjustment following a diagnosis of early-onset dementia. Journal of Aging Studies, 36, 26-32. doi:10.1016/j.jaging.2015.12.001

Roach, P., Keady, J., \& Bee, P. (2012). 'It's easier just to separate them': practice constructions in the mental health care and support of younger people with dementia and their families. Journal of Psychiatric and Mental Health Nursing, 19(6), 555-562. doi:10.1111/j.1365-2850.2011.01836.x

Sansoni, J., Duncan, C., Grootemaat, P., Capell, J., Samsa, P., \& Westera, A. (2016). 
Younger onset dementia: A review of the literature to inform service development. American Journal of Alzheimer's Disease \& Other Dementias, 31(8), 693-705. doi: $10.1177 / 1533317515619481$

Thorsen, K., Dourado, M. C. N., \& Johannessen, A. (2018). Developing dementia: The existential experience of the quality of life with young-onset dementia - A longitudinal case study. Dementia, 1471301218789990. doi:10.1177/1471301218789990

van Vliet, D., de Vugt, M. E., Bakker, C., Pijnenburg, Y. A., Vernooij-Dassen, M. J., Koopmans, R. T., \& Verhey, F. R. (2013). Time to diagnosis in young-onset dementia as compared with late-onset dementia. Psychological Medicine, 43(2), 423-432. doi:10.1017/S0033291712001122

Wawrziczny, E., Antoine, P., Ducharme, F., Kergoat, M. J., \& Pasquier, F. (2016). Couples' experiences with early-onset dementia: An interpretative phenomenological analysis of dyadic dynamics. Dementia, 15(5), 1082-1099. doi: 10.1177/1471301214554720

Willis, G. B. (2004). Cognitive interviewing: A tool for improving questionnaire design. London: Sage Publications. 
Table 1. Presentation of descriptive statistics of the study sample.

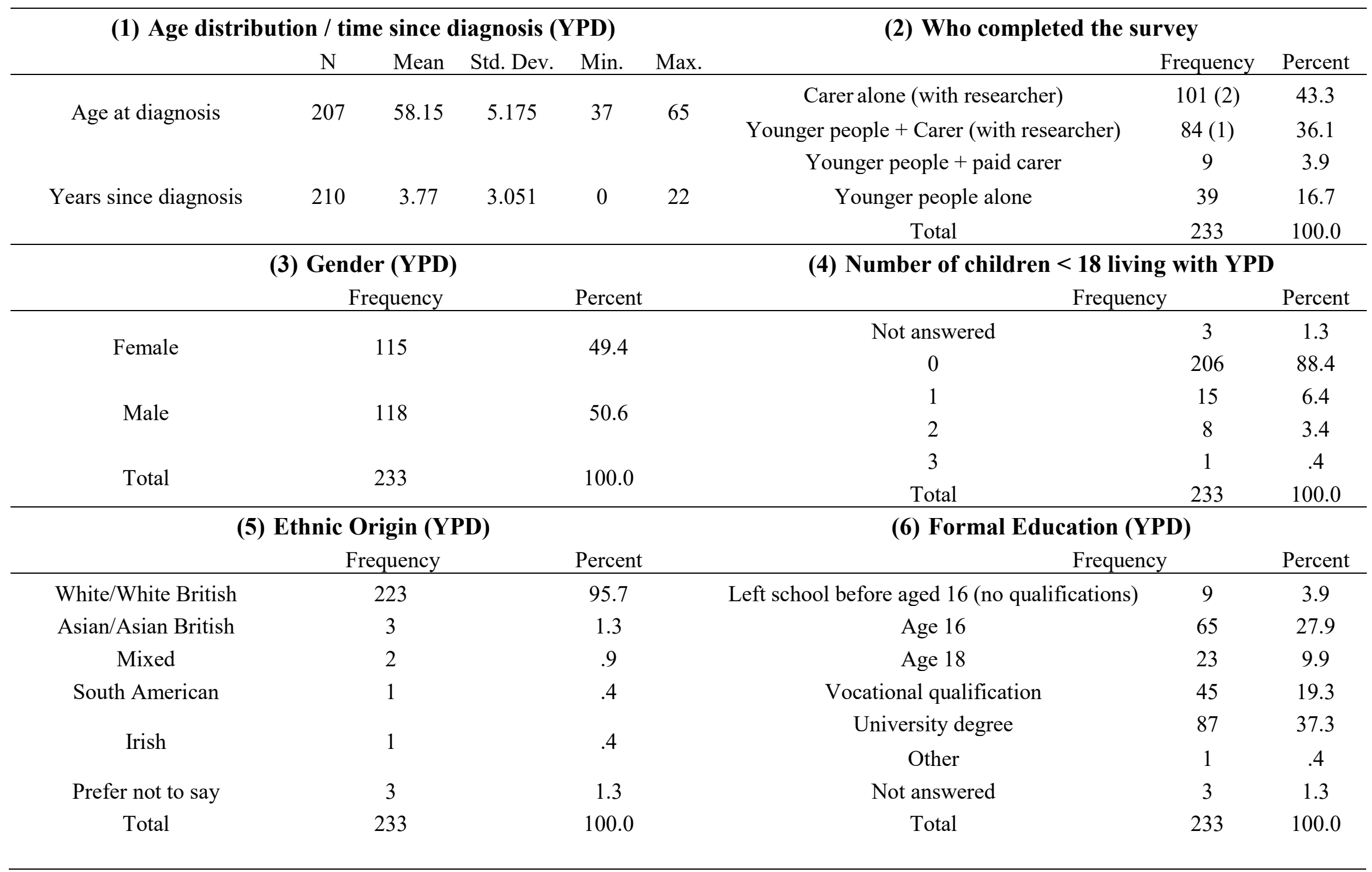




\begin{tabular}{|c|c|c|c|c|c|}
\hline \multicolumn{3}{|c|}{ (7) YPD in paid employment } & \multicolumn{3}{|l|}{ (8) YPD living alone } \\
\hline & Frequency & Percent & & Frequency & Percent \\
\hline No & 220 & 94.4 & No & 198 & 85.0 \\
\hline Yes & 13 & 5.6 & Yes & 35 & 15.0 \\
\hline Total & 233 & 100.0 & Total & 233 & 100.0 \\
\hline \multicolumn{3}{|c|}{ (9) Diagnosis (YPD) } & \multicolumn{3}{|c|}{ (10) Diagnostic services } \\
\hline & Frequency & Percent & & Frequency & Percent \\
\hline Alzheimer's & 128 & 54.9 & Young Onset Dementia Specialist Services & 25 & 10.7 \\
\hline $\begin{array}{c}\text { Frontotemporal dementia (language } \\
\text { and behavioural variants) }\end{array}$ & 30 & 12.9 & Memory clinic & 76 & 32.6 \\
\hline Vascular dementia & 21 & 9.0 & $\begin{array}{l}\text { Neurology-led } \\
\text { services }\end{array}$ & 48 & 20.6 \\
\hline $\begin{array}{c}\text { Mixed (Alzheimer's + } \\
\text { Cerebrovascular Disease) }\end{array}$ & 12 & 5.2 & Older Person Mental Health Services & 23 & 9.9 \\
\hline $\begin{array}{c}\text { Posterior Cortical Atrophy - } \\
\text { Alzheimer's Disease }\end{array}$ & 13 & 5.6 & Multiple services & 35 & 15.0 \\
\hline Lewy body dementia & 6 & 2.6 & Other & 17 & 7.3 \\
\hline Mixed (other) & 4 & 1.7 & Not answered & 4 & 1.8 \\
\hline Parkinson's dementia & 1 & .4 & Not known & 5 & 2.1 \\
\hline \multirow{2}{*}{ Unspecified } & \multirow{2}{*}{4} & \multirow{2}{*}{1.7} & Total & 233 & 100.0 \\
\hline & & & \multicolumn{3}{|c|}{ (11) YPD living in own home/care home } \\
\hline Don't know & 10 & 4.3 & & Frequency & Percent \\
\hline \multirow{2}{*}{ Not answered } & \multirow{2}{*}{4} & \multirow{2}{*}{1.7} & Not answered & 6 & 2.6 \\
\hline & & & In a care home & 15 & 6.4 \\
\hline \multirow{2}{*}{ Total } & \multirow{2}{*}{233} & \multirow{2}{*}{100.0} & In own home & 212 & 91.0 \\
\hline & & & Total & 233 & 100.0 \\
\hline
\end{tabular}

Section 1 presents the distribution of age and time since diagnosis. In section 1, N is lower than the total of 233 participants who took part in the study due to missing data. Sections 2 - 11 present the descriptive analysis of the socio-demographic information of participants. 
Table 2. Themes, sub-themes and comparison between the responses of different respondent groups.

\begin{tabular}{|c|c|c|}
\hline THEMES & SUB-THEMES & $\begin{array}{c}\text { THEME } \\
\text { REPRESENTATION }^{1}\end{array}$ \\
\hline $\begin{array}{l}\text { Specialist Advice \& } \\
\text { Information on Young } \\
\text { Onset Dementia }\end{array}$ & $\begin{array}{l}\text { Advice \& information specific to young onset } \\
\text { dementia } \\
\text { Expertise \& knowledge in young onset dementia } \\
\text { Education on young onset dementia }\end{array}$ & $\begin{array}{l}\text { All groups } \\
\text { All groups } \\
\text { All groups }\end{array}$ \\
\hline $\begin{array}{l}\text { Access to age- } \\
\text { appropriate services }\end{array}$ & $\begin{array}{l}\text { Referral on } \\
\text { Accessibility to services }\end{array}$ & $\begin{array}{l}\text { All groups } \\
\text { All groups }\end{array}$ \\
\hline $\begin{array}{l}\text { Interventions for } \\
\text { Physical and Mental } \\
\text { Health }\end{array}$ & $\begin{array}{l}\text { Cognitive functions } \\
\text { Physical Exercise } \\
\text { Medical support }\end{array}$ & $\begin{array}{l}\text { All groups } \\
\text { All groups } \\
\text { All groups }\end{array}$ \\
\hline $\begin{array}{l}\text { Opportunities for } \\
\text { Social Participation }\end{array}$ & $\begin{array}{l}\text { Camaraderie } \\
\text { Meaningful social engagement } \\
\text { Recreational activities } \\
\text { Sharing with others } \\
\text { Transport }\end{array}$ & $\begin{array}{c}\text { All groups } \\
\text { All groups } \\
\text { All groups } \\
\text { YPD/YPD+Carer } \\
\text { Carers } \\
\end{array}$ \\
\hline $\begin{array}{l}\text { Opportunities to Have a } \\
\text { Voice }\end{array}$ & $\begin{array}{l}\text { Participation in research } \\
\text { Raising awareness on young onset dementia } \\
\text { Educating others } \\
\text { Advocacy }\end{array}$ & $\begin{array}{l}\text { All groups } \\
\text { All groups } \\
\text { YPD+Carer/Carers } \\
\text { All groups }\end{array}$ \\
\hline $\begin{array}{l}\text { Enablement of } \\
\text { Independence while } \\
\text { Managing Risk }\end{array}$ & $\begin{array}{l}\text { Assistive technology } \\
\text { Outdoor independence } \\
\text { Indoor safety }\end{array}$ & $\begin{array}{c}\text { Carers } \\
\text { Carers } \\
\text { YPD/Carers }\end{array}$ \\
\hline $\begin{array}{l}\text { Enablement of } \\
\text { Financial Stability }\end{array}$ & $\begin{array}{l}\text { Maintaining employment } \\
\text { Flexible working for carer } \\
\text { Benefits } \\
\text { Externally funded care }\end{array}$ & $\begin{array}{l}\text { Carers } \\
\text { YPD+Carer } \\
\text { All groups } \\
\text { Carers } \\
\end{array}$ \\
\hline $\begin{array}{l}\text { Support interventions } \\
\text { for family relationships }\end{array}$ & $\begin{array}{l}\text { Relational interventions } \\
\text { Balanced roles and tasks }\end{array}$ & $\begin{array}{l}\text { All groups } \\
\text { YPD }\end{array}$ \\
\hline
\end{tabular}

\section{${ }^{1}$ KEY}

'YPD' indicates the sub-theme included responses from surveys completed by YPD alone and/or YPD with the help of a paid carer.

'YPD+Carer' indicates the sub-theme included responses from surveys completed jointly by YPD and a family carer

'Carers' indicates the sub-theme included responses from surveys completed by family carers alone

'All' groups indicates the sub-theme included responses from all the above. 
Figure 1. Visual representation of the objectives of positively experienced services, as reported by the study participants. The figure indicates the focus of services on enabling agency via an enabling-protective circle that supports YPD to re-establish and/or maintain a positive identity.

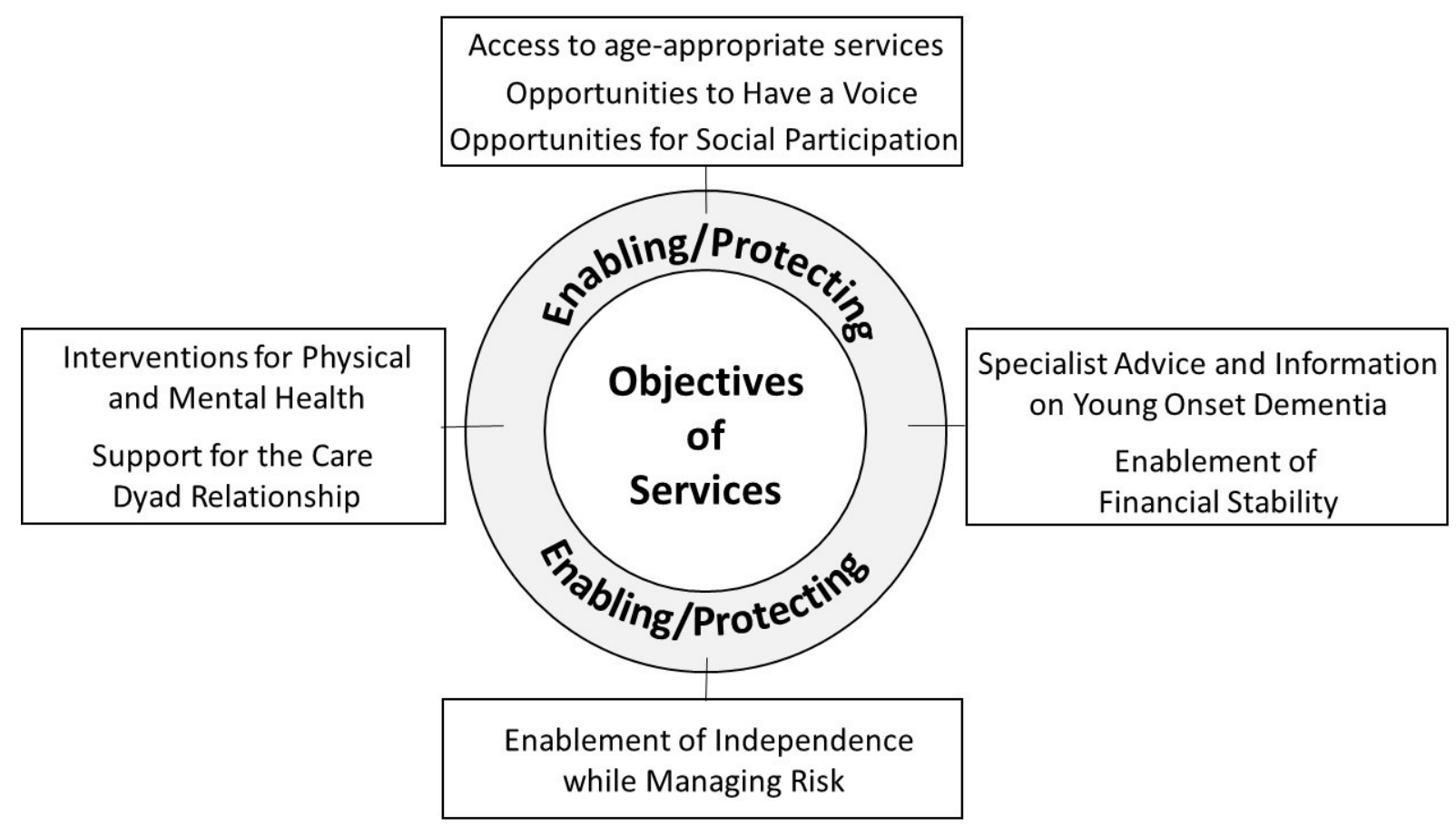

To be printed in black and white 